\title{
Clothing Fashion Design Competency instrument: an application of rasch measurement model
}

\begin{abstract}
Clothing Fashion Design Competency (CFaDC) instrument has been developed to measure the knowledge of instructors in order to become an educator who can implement effective teaching processes, as well as master various competencies to deliver the teachings according to the academic standards. This study aims to determine item/respondent reliability index, item/respondent separation index, item polarity, item difficulty level and respondents' ability, as well as unidimensionality. A total of 330 instructors in the field of fashion and clothing have answered the $\mathrm{CFaDC}$ instrument. The instrument consists of 5 constructs, namely design knowledge, clothing construction, clothing selection, clothing care and textiles. The validation of the instrument applied psychometric characteristics of assessment procedures using Rasch measurement model. The findings showed that the item reliability index was high and acceptable. Meanwhile, respondents' ability level could be divided into two levels in this study. Moreover, it was found that there was no second dimension in measuring the constructs in $\mathrm{CFaDC}$ instrument. The results revealed that out of 85 items, 54 items were retained, whereas 31 items were detected as misfits and should be dropped so that this instrument is fair and reliable to all respondents. The results of this study will be pointing towards the stability of standard of competencies for Clothing Fashion ( $\mathrm{CFaD}$ ) program in order for the program to always be updated and in tandem with the needs of today's clothing and apparel industry.
\end{abstract}

Keyword: Clothing fashion design; Knowledge competencies; Rasch measurement model 